\title{
Classification and Analysis of Switched Reluctance Converters
}

\author{
Jin-Woo Ahn*, Jianing Liang** and Dong-Hee Lee ${ }^{\dagger}$
}

\begin{abstract}
This paper reviews and analyzes converters for SRM(Switched Reluctance Motor) drive. Conventional classification focuses on the number of power switches and diodes. It is easy to find the number of semiconductors and the cost by counting the number of active components, but it does not show the important characteristics of a power converter. The voltage ratings for the power switches and diodes are also difficult to identify. This paper proposes a switched reluctance (SR) converter configuration that is classified based on the commutation type and magnetic energy path. The converter has three parts: utility interface, front-end circuit, and power converter. Based on the overview on the conventional SR drive, the most important characteristic of the converter is determined by the topology of front-end in conjunction with the power converter. An SR converter has two parts: front-end and power converter. Inasmuch as the capacitive front-end is widely used for voltage source converters, this paper focuses on topologies for the front-end.
\end{abstract}

Keywords: SRM, converter, Classification, SR Converter, Front-end

\section{Introduction}

Switched reluctance (SR) motors have a simple and robust construction; they eliminate permanent magnets, brushes, commutators, and coil windings in the rotors. As a result of its inherent simplicity, SR motors offers advantages of reliable and low-cost variable-speed drives [1]-[2].

The entire SR drive system includes a motor, position detector, converter, and controller. The motor is used for electromechanical energy conversion from electrical to mechanical form. The position detector detects the rotor position because phase excitation pulses need to be properly synchronized to the rising region of the inductance profile for motoring operation. The converter is a power supply unit that follows the commands of the controller to energize each phase of the motor at the appropriate times. Therefore, it does not only deliver energy to an electronic

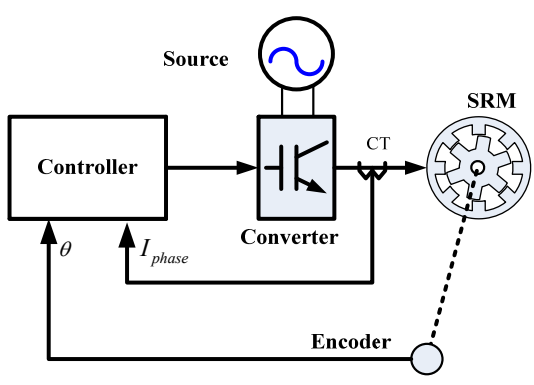

Fig. 1. Block diagram of SR drive.

$\dagger \quad$ Corresponding Author: Dept. of Mechatronics Engineering, Kyungsung Univerity, Korea. (leedh@ks.ac.kr)

* Dept. of Mechatronics Engineering, Kyungsung Univerity, Korea. (jwahn@ks.ac.kr)

** Shenzhen Institutes of Advanced Technology, Chinese Academy of Sciences, and The Chinese University of Hong Kong, China. (1jn000@gmail.com)

Received: May 24, 2010; Accepted: August 6, 2010 device from an electrical outlet, it also regulates the current to meet specific device requirements. The controller regulates SRM performance. The control block of the SR drive is shown in Fig. 1. An integrated SR drive system requires several technologies: motor design, position detecting method, converter topology, and control strategy.

\section{Characteristics of SR Converter}

One of the key topics for research in SR drives is the converter topology design. The performance of the SR drive is highly affected by the performance and characteristic of converters. Conventional SRM converters are commercially available, and phase independence and unipolar current are applied widely in industrial applications. Several varieties of converter topologies have been presented in the last 30 years [3]-[6]. With continued research, different topologies have emerged presenting reduced numbers of power switches [18]-[23], faster excitation time [24][25], faster demagnetization time [16]-[25], high efficiency [26]-[34], high power factor, and high power [35]-[43].

In accordance with the operational characteristic of the SR motor, the converter has some basic requirements:

1. Each phase of the SR motor should be able to conduct independently. It means that one phase has at least one switch for motor operation.

2. The converter should be able to demagnetize the phase before it steps into the regenerating region. If the machine is operating as a motor, it should be able to excite the phase before it enters the generating region. To improve the performance, the converter must satisfy the following additional requirements: (1) allow phase overlap control; (2) utilize the demagnetization energy from the outgoing phase in a useful way either by feeding it back to the source (DC-link capacitor) or by using it in 
the incoming phase; (3) generate sufficiently high negative voltage for the outgoing phase given a short commutation period in order to reduce demagnetization time; (4) use the freewheel during the chopping period to reduce switching frequency; (5) support high positive excitation voltage for building up a higher phase current, which may improve the output power of motor; (6) acquire resonant circuit in order to apply zero-voltage or zero-current switching, and to reduce switching loss; and (7) apply power factor correction circuit in order to improve the power factor.

\subsection{Basic Components of SR Converter}

The block diagram of a conventional SRM converter is shown in Fig. 2. It can be divided into utility, AC/DC converter, capacitor network, DC/DC power converter, and SR motor.

In this paper, the converter for the SRM drive is conveyed in three parts: utility interface, front-end circuit, and power converter (Fig. 3). The front-end and the power converter are called "SR converter" in this paper.

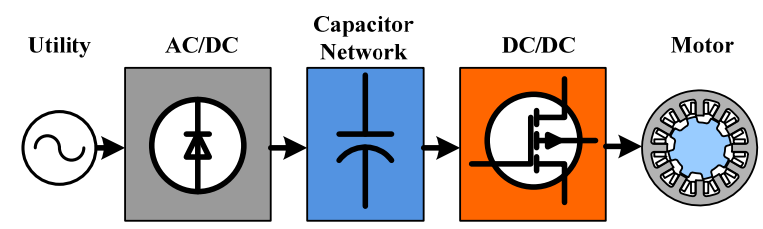

Fig. 2. Component block diagram of conventional SR drive.

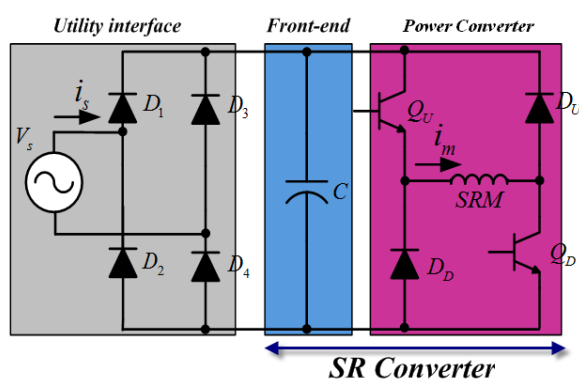

Fig. 3. Modules of SR drive.

\subsection{Utility Interface}

The main function of the utility interface is to rectify AC to $\mathrm{DC}$ voltage. The line current input from the source needs to be sinusoidal and in phase with AC source voltage. The

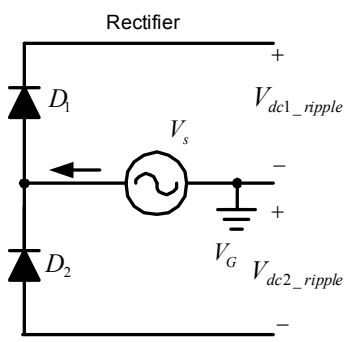

(a) Voltage double rectifier

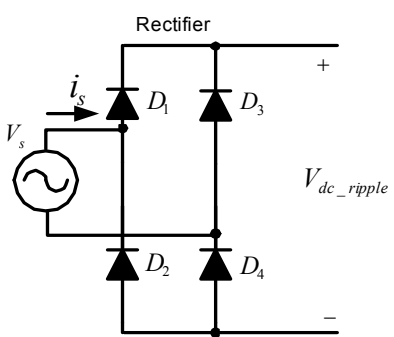

(b) 1-ph. diode bridge rectifier

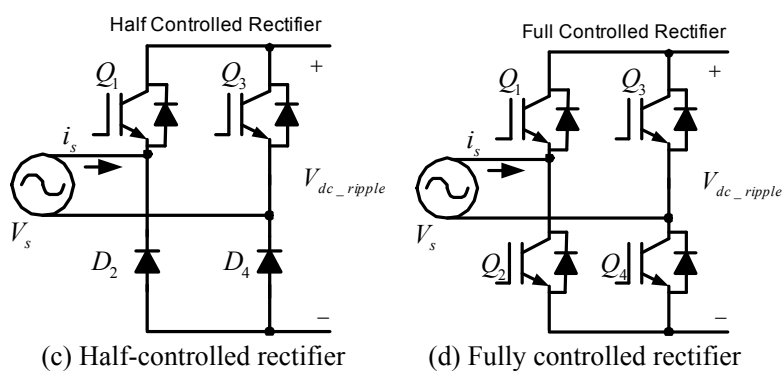

Fig. 4. Utility interface.

$\mathrm{AC} / \mathrm{DC}$ rectifier provides the $\mathrm{DC}$ bus to the $\mathrm{DC} / \mathrm{DC}$ converter. Typically, a simple voltage doubler, and diode bridge rectifier are popularly used in SR drives.

\subsection{Front-end Circuit}

With high voltage ripple of rectifier output, a large capacitor is connected as a filter on the DC-link side in the voltage source power converter. This capacitor is charged to a value close to the peak of the $\mathrm{AC}$ input voltage. As a result, the voltage ripple is reduced to an acceptable valve (i.e., if the smoothing capacitor is big enough). However, during heavy load conditions, a higher voltage ripple exhibits twice the line frequency. For the SR drive, another important function is that the capacitor should store the circulating energy when the phase winding returned to.

To improve the performance of the SR drive, one or more power components are added. In this paper, for reasonable implementation, two capacitor networks are considered with no inductance at the front end. Two types of capacitor networks are introduced: a two-capacitor network with diodes and two capacitors with an active switch. The maximum boost voltage can be twice times of the DC-link voltage.

The two-capacitor network with diodes (i.e., a passivetype circuit) is shown in Fig. 7. The output voltages of the series and parallel type front-ends are not controlled. The detailed analysis of its characteristics is presented in Table 1.

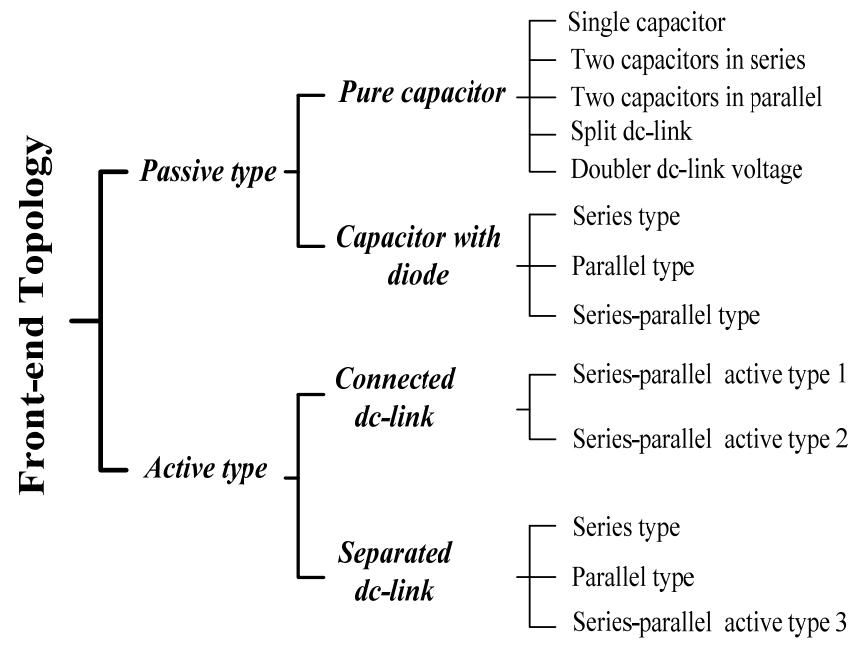

Fig. 5. Classification of capacitive-type front-end topology. 


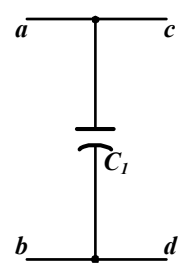

(a) Single cap.

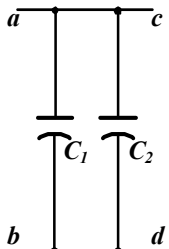

(c) Two cap. in parallel

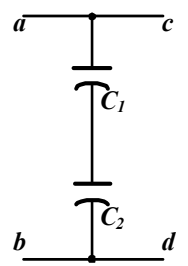

(b) Two cap. in series

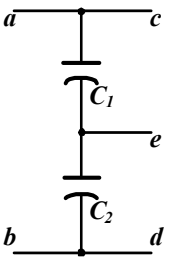

(d) Split dc-link

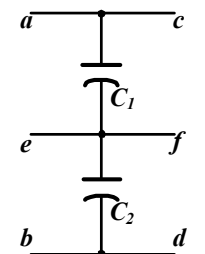

(e) Doubler dc-link voltage

Fig. 6. Pure capacitor network.

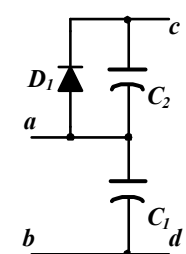

(a) Series type

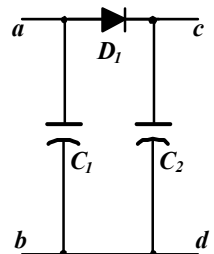

(b) Parallel type

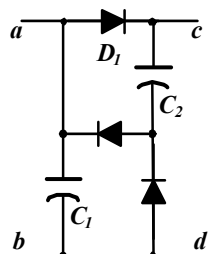

c) Series-parallel type

Fig. 7. Two capacitor network with diodes.

Table 1. Characteristics of a two-capacitor network with diodes

\begin{tabular}{c|c|c|c}
\hline Type & Series & Parallel & Series-parallel \\
\hline No. of Cap. & 2 & 2 & 2 \\
\hline No. of Diode & 1 & 1 & 3 \\
\hline$V_{\text {boost }}$ & $V_{C 1}+V_{C 2}$ & $V_{C 2}$ & $V_{C 1}+V_{C 2}$ \\
\hline$V_{d c}$ & $V_{D C}$ & $V_{D C}$ & $V_{D C}$ \\
\hline Spec. Boost Cap. & $V_{D C}$ & $V_{\text {boost }}$ & $V_{D C}$ \\
\hline Spec. Diode & $V_{D C}$ & $V_{D C}$ & $V_{D C}$ \\
\hline \multicolumn{4}{|r}{}
\end{tabular}

The active type of the two-capacitor network connected to the DC-link, which is a two-output terminal active boost circuit, is shown in Fig. 8 and Table 2.
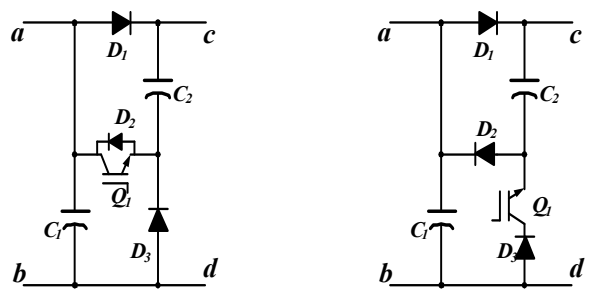

a) Series-parallel active type 1

(b) Series-parallel active type 2

Fig. 8. Active type of two capacitors connected to DC-link.

Table 2. Characteristics of the active type connected to DC-link

\begin{tabular}{c|c|c}
\hline Type & Series-parallel 1 & Series-parallel 2 \\
\hline No. of Cap. & 2 & 2 \\
\hline No. of Sw. & 1 & 1 \\
\hline No. of Diode & 2 & 3 \\
\hline$V_{\text {boost }}$ & $V_{C 1}+V_{C 2}$ & $V_{C 2}$ \\
\hline$V_{\text {demag }}$ & $-\left(V_{C 1}+V_{C 2}\right)$ & $-\left(V_{C 1}+V_{C 2}\right)$ \\
\hline Dc-link & $V_{D C}$ & $V_{D C}$ \\
\hline Spec. Boost Cap. & $V_{D C}$ & $V_{b o o s t}$ \\
\hline Spec. Diode & $V_{D C}$ & $V_{D C}$ \\
\hline
\end{tabular}

\section{Analysis of the Converter}

A well-known classification of SRM converters that consider only the number of power switches and diodes is introduced [2]. The characteristics of this novel classification, which contrasts the conventional classification, are proposed [6]-[11].

The classification of the power converter focuses on the number of power switches and diodes. These options have

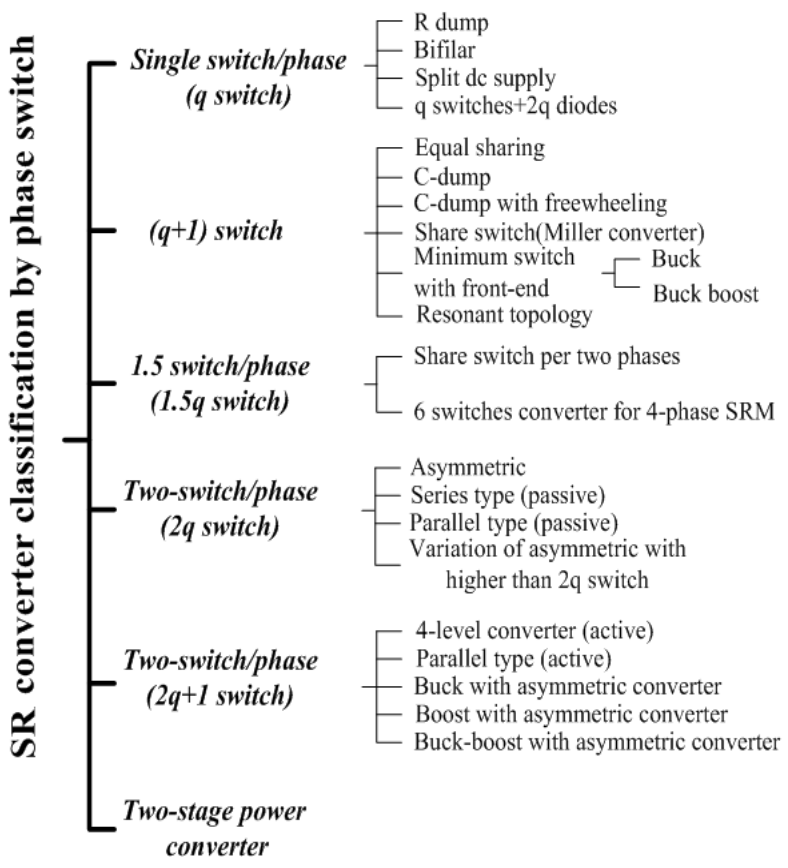

Fig. 9. SR converter configuration by phase switch. 
given way to power converter topologies with $\mathrm{q},(\mathrm{q}+1)$, $1.5 q$, and $2 q$ switch topologies, where $q$ is the number of motor phases. These configurations are classified and listed in Fig. 9 for easy reference [2], [12]. A two-stage power converter configuration, which does not fit this categorization based on the number of machine phases, has also been included.

All of the converter topologies, except the two-stage power converter, assume that a DC voltage source is available for their inputs. This DC source may come from batteries or the more usual rectified AC supply with a filter, which can provide stable DC input voltage to SR converters.

With the classification, even though it is easy to find the number of semiconductors and related costs by counting the number of active components, it does not show important characteristics of a power converter. Specifically, the voltage ratings for the power switches and diodes are difficult to determine.

\subsection{SR Converter by Commutation}

Different converters having the same number of switches may obtain different performance and characteristics. From this point of view, such classification is not useful in determining the characteristics of an SRM converter.

Another switched reluctance drive converter classification has been proposed in [5]. The three types of classifications are extra commutation, half bridge, and selfcommutation. In the extra commutation circuit, the capacitive, magnetic, and dissipative circuits are utilized. However, the distinction between these three types has not been defined clearly. The conventional half bridge and the selfcommutation circuit require large capacitors in the frontend and hence, can also be classified as capacitive circuit.

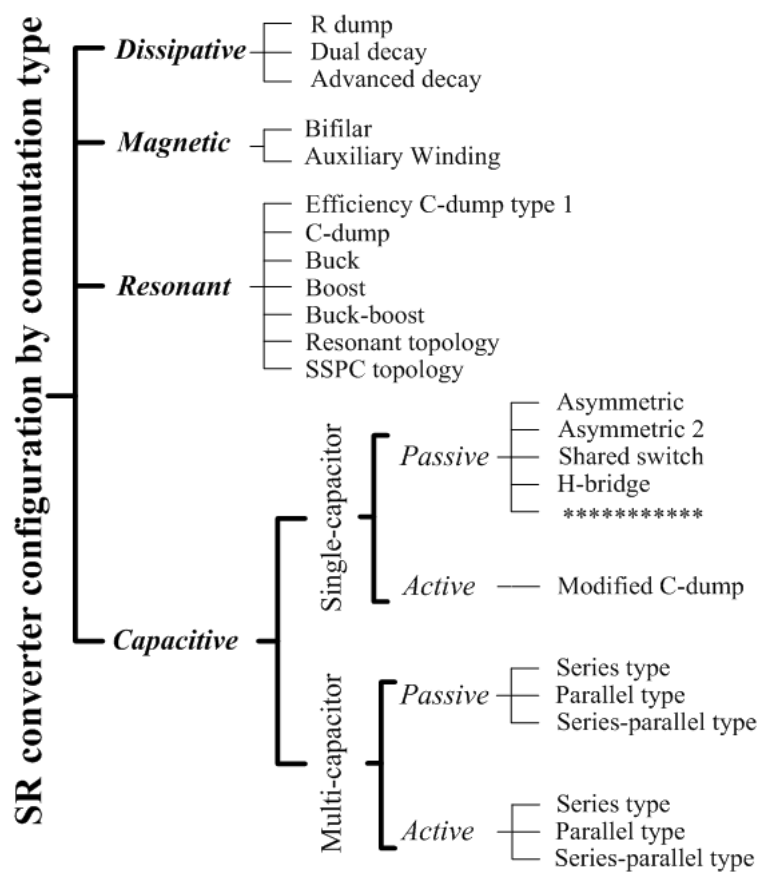

Fig. 10. SR converter configuration by commutation type.
The characteristics of the circuits, which contain one or more inductances, are not shown in the classification [7-9].

An SR converter configuration by commutation type is proposed in Fig. 10. In accordance with the commutation type of the most commonly returned or dissipated stored magnetic energy, four major types can be classified as dissipative, magnetic, resonant, and capacitive. For discussion purposes, the capacitive converter category is split into several subclasses in this paper. The concepts for passive and active converters are also introduced. The distinction between active and passive is determined whether they include a controllable power switch or not.

\subsection{Dissipative Converter}

The dissipative type disperses some or all of the stored magnetic energy using a phase resistor, external resistor, or both. The remaining energy is transformed into mechanical energy. Therefore, none of the stored magnetic energy in the phase winding is returned to the DC-link capacitor or the source. The advantage of this type of converter can be attributed to its simplicity, low cost, and low count in terms of semiconductor components [12], [13].

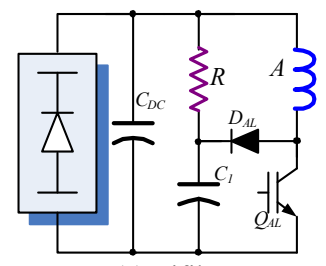

(a) Bifilar

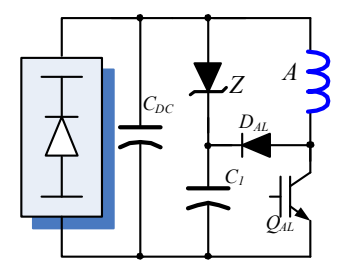

(b) Single controllable switch
Fig. 11. Two types of magnetic SR converters.

\subsection{Resonant Converter}

The resonant type has one or more external inductances for buck, boost, or resonant purposes [15]-[17]. In general, the inductance, diode, and power switch are designed as a snubber circuit, making the dump voltage easy to control, as well as providing for low voltage for easy boost. In special cases, inductance is used to construct a resonant converter. This process allows the voltage of the phase winding to be regulated by a snubber circuit. However, adding inductance, among others, increases the size and cost of the converter. The addition of other components also increases the converter cost.

Three resonant types are shown in Fig. 12, all of which use a snubber circuit composed of a power switch, diode, and inductance.

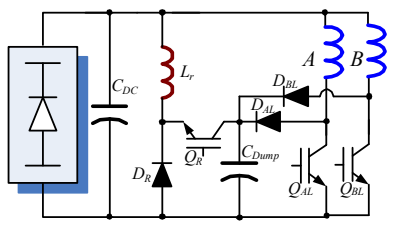

(a) C-dump

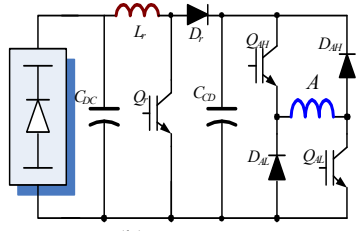

(b) Boost 


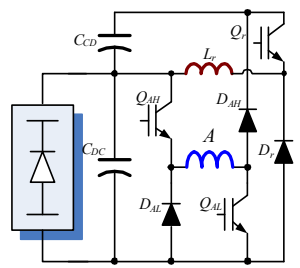

(c) High demagnetization

Fig. 12. Three types of resonant SR converters.

\subsection{Capacitive Converter}

The magnetic energy in the capacitive converters is fed directly back to the boost capacitor, the DC-link capacitor, or both. Compared with dissipative, magnetic, and resonant converters, another component is present in the main circuit of a capacitive converter to increase the additional loss. Unlike other converters, this stored magnetic energy can be fed easily back to the converter by using only the inductance of phase winding. Although the capacitor exhibits equivalent series resistance (ESR), the loss of ESR is lower than in other converters. Therefore, a capacitive converter is more effective for SR drive use. Several capacitive converters have been presented in the past 20 years [2]-[17].

The capacitive converter can be divided two types: single capacitor and multi-capacitor type.

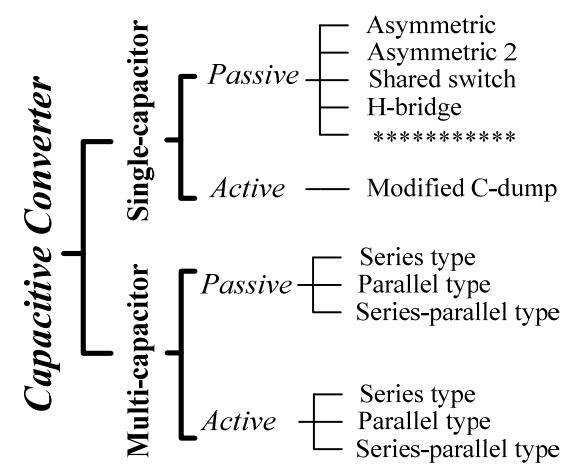

Fig. 13. Classification of capacitive SR converter.

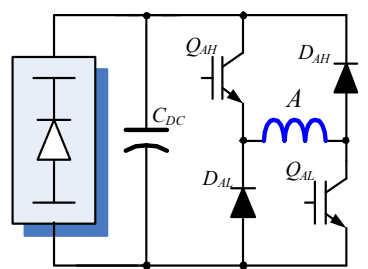

(a) Asymmetric

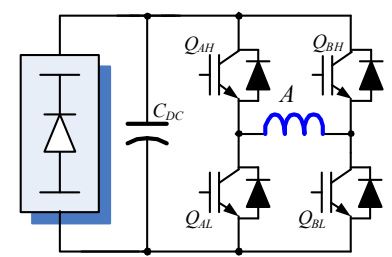

(c) H-bridge

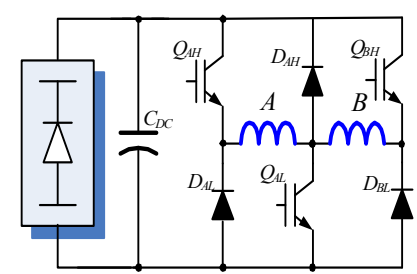

(b) Shared switch

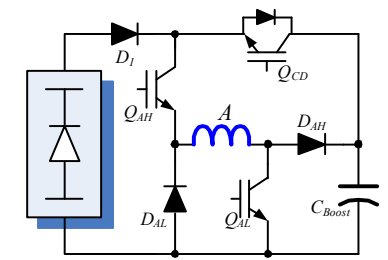

(d) Modified C-dump

\section{1) Single-capacitor Converter}

Single-capacitor converters have a simple structure, hence making them very popular. Four single capacitor types are shown in Fig. 14. One capacitive converter has a simple front-end, as shown in Figs. 14(a)-(c) [1]-[3]. This capacitor should be large enough to remove the voltage ripple of the rectifier, after which it can then store magnetic energy. Since the DC-link capacitor voltage is uncontrollable during charging and discharging, this type of converter is referred to as a passive converter. The modified C-dump converter is shown in Fig. 14(d) [16], [17]. In this converter, the boost capacitor only stores the recovered energy in order to build up boost voltage. Unfortunately, one power switch should be placed in front of the boost capacitor for it to control the voltage. The fluctuating DC-link voltage is affixed directly to the phase winding because the boost capacitor does not reduce DC-link voltage from the rectifier. The boost capacitor only requires enough room for the stored magnetic energy; therefore, the size of this capacitor is smaller than conventional DC-link capacitors. The single capacitor in capacitive converters simplifies the construction of converters. However, the input voltage for the phase winding is affixed by the DC-link capacitor. If only boost capacitor is used, the DC-link voltage fluctuates. This requires an additional power switch to control the boost voltage. However, this extra switch would increase the cost of the converter.

\section{2) Multi-capacitor Converter}

Multi-capacitor converters include two or more capacitors in their topology in order to obtain boost voltage. However, an extra capacitor would complicate the topology of the converter. In this paper, different converter topologies, which include two capacitors, are considered. The different types of passive-type front-ends are shown in Fig. 15. The passive converter with two capacitors in parallel type is shown in Fig. 15(a) [7]. Given the direction of diode, the stored magnetic energy is fed back to the boost capacitor. Maximum boost voltage can be obtained by a suitable size of the capacitor. The voltage of the boost capacitor is changed by the stored magnetic energy at different operating conditions because the discharge of the boost capacitor is uncontrollable in a passive converter. When the phase switch is turned on, the voltage of the boost capacitor might fall swiftly until the voltage reaches the DC-link voltage. Given the non-linear characteristic of the SR motor, it is difficult to estimate its corresponding advance or turn-on angle.

A passive converter with two capacitors in series is shown in Fig. 15(b) [7]. The stored magnetic energy charges the two capacitors in a series. Therefore, a part of the energy is stored in the boost capacitor. This then builds up boost voltage, thereby offering the same advantage as parallel passive converters. However, the voltage rating of boost capacitors is less than parallel converters.

Fig. 14. Single capacitor type in capacitive SR converter. 


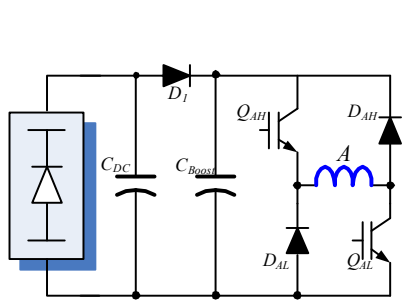

(a) Parallel type

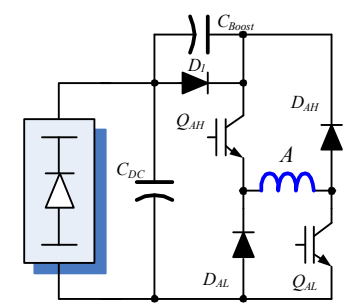

(b) Series type

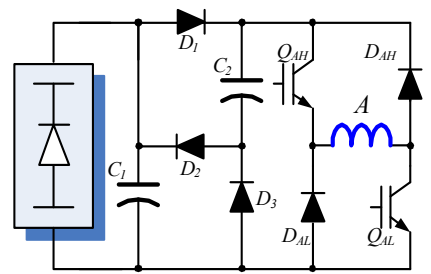

(c) Series-parallel type

Fig. 15. Passive boost converter with two capacitors.

Another passive converter for the two-capacitor seriesparallel type is shown in Fig. 15(c) [7]. This converter is composed of a rectifier, the proposed passive boost circuit, and an asymmetric converter. Excitation voltage corresponds to the DC-link voltage. However, the demagnetization voltage is twice than the DC-link voltage. A high demagnetization voltage reduces the tail current and negative torque; it also extends the dwell angle to increase output.

Two other passive SR converters with two-series capacitors is shown in Fig. 16 [7]. The front-end and DC-DC converter are same, but with the bridge rectifier and the voltage-doubling rectifier connected. The split DC-link converter is shown in Fig. 16(a). The phase voltage of this converter is half of the DC-link voltage. The double dc-link voltage converter is shown in Fig. 16(b) [8]. The phase voltage is same as the DC-link voltage. The main advantage of these two converters is the ability to use one switch and one diode per phase. However, the voltage rating of the power switch and the diode is twice than in the input excitation voltage.

The active boost converter with two capacitors connected in parallel is shown in Fig. 17. The four active boost converters are introduced. To handle the charging of the capacitor at the beginning of the conduction period, one diode forms a series or becomes parallel with the power switch (i.e., to protect the power switch). When parallel types 1 and 2 are used with the asymmetric converter, the

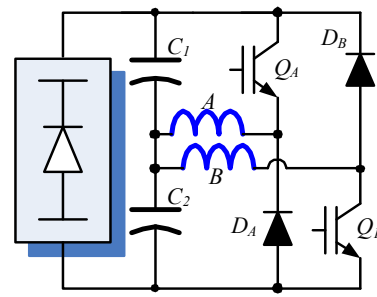

(a) Split dc-link type

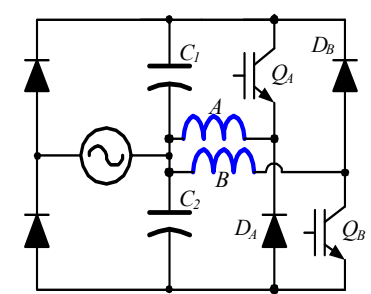

(b) Doubler dc-link voltage type
Fig. 16. Other passive SR converter with series for the capacitor type. maximum voltage rating of the power diode and the switch exhibits similarly as with the desired boost voltage. While the diode is connected to the power switch, the boost capacitor is only charged by the stored magnetic energy. At the onset, the voltage of the boost capacitor is increased from 0 to the desired value. For the parallel converter (type 2), a diode parallel to the power switch causes the DC-link capacitor to charge the boost capacitor. Parallel converters of types 3 and 4, which belong to capacitor dump converters, are shown in Figs. 17(c) and (d) [9]. If the demagnetization voltage is the same as with the DC-link, the voltage rating of power diode and switch reaches at least twice the DC-link voltage.

An active boost converter with two series-connected capacitors is shown in Fig. 18(a) [9]. Stored magnetic energy charges these capacitors, thereby causing the boost voltage to build up in the boost capacitor. Power switch $\mathrm{Q}_{\mathrm{cd}}$ is used to control this specific boost voltage.

An active boost converter with a series-parallel connection for the two capacitors is shown in Fig. 18(b) [9]. The active capacitor circuit added to the front-end consists of three diodes and one capacitor. This circuit combines a series-connected and a parallel-connected structure in the two capacitors. Based on this active boost capacitor network, the two capacitors can be connected in series or in parallel at different modes of operation. The operation mode of whole converter has been reported previously [9]. Fast excitation and demagnetization are obtained easily from the two series-connected capacitors. A stable voltage is achieved by using the two parallel-connected capacitors.

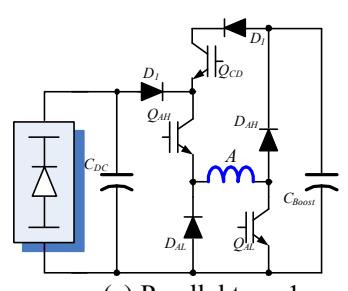

(a) Parallel type 1

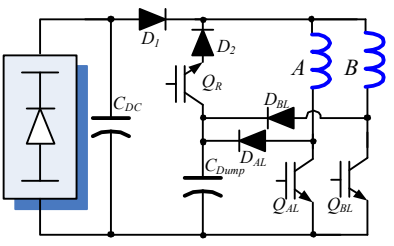

(c) Parallel type 3

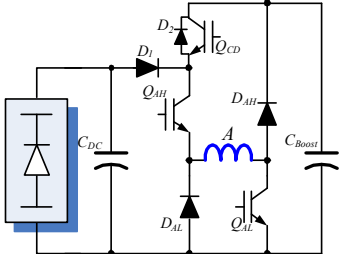

(b) Parallel type 2

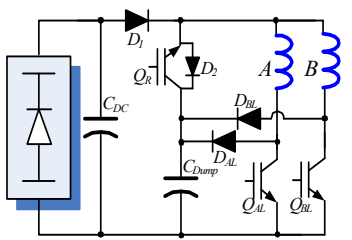

(d) Parallel type 4
Fig. 17. Active boost converter with parallel capacitors.

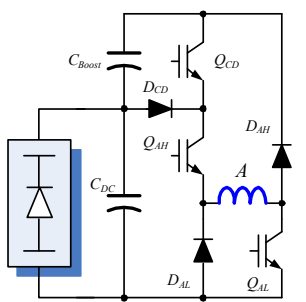

(a) Series capacitor type

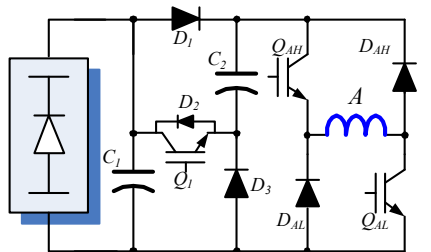

(b) Series-parallel capacitor type
Fig. 18. Active boost converter. 
Table 5. Comparison of 2-capacitor types

\begin{tabular}{c|c|c|c|c}
\hline & Asymmetric & $\begin{array}{c}\text { 2-capacitor } \\
\text { In series type }\end{array}$ & $\begin{array}{c}\text { 2-capacitor In } \\
\text { parallel type }\end{array}$ & $\begin{array}{c}\text { 2-capacitor in } \\
\text { series-parallel }\end{array}$ \\
\hline $\mathrm{V}_{\max }$ & $\mathrm{V}_{\mathrm{dc}}$ & $\infty / 2 \mathrm{~V}_{\mathrm{dc}}$ & $\infty / 2 \mathrm{~V}_{\mathrm{dc}}$ & $2 \mathrm{~V}_{\mathrm{dc}}$ \\
\hline $\mathrm{V}_{\text {control }}$ & $\mathrm{No}$ & $\mathrm{Yes}$ & Yes & optional \\
\hline $\mathrm{V}_{\mathrm{C} 1 \text { rate }}$ & $\mathrm{V}_{\mathrm{dc}}$ & $\mathrm{V}_{\mathrm{dc}}$ & $\mathrm{V}_{\mathrm{dc}}$ & $\mathrm{V}_{\mathrm{dc}}$ \\
\hline $\mathrm{V}_{\mathrm{C} 2 \text { rate }}$ & $\mathrm{V}_{\mathrm{dc}}$ & $\infty / \mathrm{V}_{\mathrm{dc}}$ & $\infty / 2 \mathrm{~V}_{\mathrm{dc}}$ & $\mathrm{V}_{\mathrm{dc}}$ \\
\hline No. Switch & 2 & 3 & 3 & 3 \\
\hline No. Diode & 2 & 3 & 3 & 4 \\
\hline Stability & Good & Normal & Normal & Good \\
\hline
\end{tabular}

Four types of converters are compared in Table 5. The converter with two capacitors connected in series, or the converter with two capacitors connected in parallel, can obtain higher boost voltage than the series-parallel converter. However, an increased boost voltage increases converter cost. Since the series-parallel converter can limit the maximum voltage to twice the DC-link voltage, it is more stable and controllable.

\section{Conclusion}

This paper has addressed and analyzed converters for the SR drive. Power converters for the SR drive can be divided into three parts: utility interface, front-end circuit, and SRM converter. Based on an overview on conventional SR drive, the most important characteristic of the power converter can be determined by their front-end topologies. Accordingly, inasmuch as the capacitive front-end is widely used for voltage source converters, this paper focused on the topologies for this type. The topology of purely capacitive front-ends is classified as either passive or active. The concept of a series-parallel connection for the capacitors is also described. A novel classification of power converters is introduced based on the commutation type, thereby highlighting the important commutation characteristics of SR converters.

\section{Acknowledgement}

This research was supported by Kyungsung University Research Grants in 2010

\section{References}

[1] J. W. Ahn, "Switched Reluctance Motor"(Korean), Osung Media, 2004.

[2] R. Krishnan, "Switched Reluctance Motor Drives: Modeling, Simulation, Analysis, Design, and Applications," CRC Press, 2001.

[3] S. Vukosavic and V.R. Stefanovic, "SR motor inverter topologies: A comparative evaluation," IEEE Tr. IAS, pp.946-958, 1990.

[4] T.J.E. Miller, "Electronic control of switched reluctance machines," Newnes, 2001.
[5] A. Ayob, V. Pickert, H. Slater, "Overview of low cost converters for single-phase switched reluctance motors," Power Electronics and Applications, European Conference. pp. 10, 2005.

[6] M. Barnes, and C. Pollock, "Power electronic converters for switched reluctance drives," IEEE Trans. Power Electronics, Vol. 13, Issue 6, pp.1100-1111, 1998.

[7] D.H. Lee, J. Liang, T.H. Kim, J.W. Ahn, "Novel passive boost power converter for SR drive with high demagnetization voltage," International Conference on Electrical Machines and Systems, 2008, pp.33533357, 17-20 Oct. 2008.

[8] Weng Thong, C. Pollock, "Two phase switched reluctance drive with voltage doubler and low dc link capacitance," Industry Applications Conference, 2005. Vol. 3, pp.2155-2159, 2-6 Oct. 2005.

[9] J. Liang, S.H. Seok, D.H. Lee, J.W. Ahn, "Novel active boost power converter for SR drive," International Conference on Electrical Machines and Systems, 2008, pp.3347-3352, 17-20 Oct. 2008.

[10] B. Francoeur, H. Le-Huy, and P. Viarouge, "Unipolar converters for switched reluctance motors", IEEEIAS Conf. Rec., pp.551-560, 1989.

[11] A. Dahmane, F. Meebody, F.-M. Sargos, "A novel boost capacitor circuit to enhance the performance of the switched reluctance motor," PESC 2001, pp.844849, June 2001.

[12] R.M. Davis, and R.J. Blake, "Inverter drive for switched reluctance motor circuits and component ratings," IEE Proc., pp.126-136, 1981.

[13] R. Krishnan, and P. Materu, "Design of a singleswitch-per-phase converter for switched reluctance motor drives," IEEE Trans. on Industrial Electronics, Vol. 37, Issue 6, pp.469-476, 1990.

[14] W.F. Ray, and R.M. Davis, "Inverter drive for doubly salient reluctance motor: its fundamental behaviour, linear analysis and cost implications," Electric Power Applications, pp.185-193, 1979.

[15] M. Ehsani, J.T. Bass, T.J.E. Miller, and R.L. Steigerwald, "Development of a unipolar converter for variable reluctance motor drives," IEEE Trans. Ind. Appl., Vol. 23, No. 3, pp.545-553, 1987.

[16] A.M. Hava, V. Blasko, T.A. Lipo, "A modified Cdump converter for variable-reluctance machines," Industry Applications, IEEE Transactions on Vol. 28, Issue 5, pp.1017-1022, Sept.-Oct. 1992.

[17] S. Mir, I. Husain, M.E. Elbuluk, "Energy-efficient Cdump converters for switched reluctance motors," Power Electronics, IEEE Transactions on Vol. 12, Issue 5, pp.912-921, Sept. 1997.

[18] A.M. Staley, R. Krishnan, "Single controllable switch power converter for SR motor drive systems," Industrial Electronics Society, 2005. IECON 2005. 31st Annual Conference of IEEE pp.6, 6 Nov. 2005.

[19] C. Pollock and Williams B. W., A unipolar Converter for a Switched reluctance Motor, IEEE IAS, 44-49, 1988 
[20] G.R. Dunlop, "Power device reduction using negative torque sequences in switched reluctance motor," ICEM, 595-598, 1998.

[21] C. Pollock and B.W. Williams, "Power converter circuits for switched reluctance with the minimum number of switches," IEE Proc., Vol. 137, Pt. B, No. 6, pp.373-384, 1990.

[22] R. Krishnan and P. Materu, Analysis and design of a low cost converter switched reluctance motor drives, IEEE Trans. on Industry Appl., 29(2), 320-327, 1993.

[23] R. Krishnan and P. Materu, Analysis and design of a new converter for switched reluctance motor drives, IEEE IAS, 1181-1185, 1989

[14] J. Liang, D.H. Lee, J.W. Ahn, Y.J. An, “A Novel 4Level Converter for High Speed SR Drive," Power Electronics Specialists Conference, 2006. PESC '06. 37th IEEE, pp.1-6, 18-22 June 2006.

[15] S.H. Lee, S.H. Park, S.G. Oh, J.W. Ahn; "Five-Level Inverter for Optimal Excitation of SRM Drive," Proceedings of IEEE/ISIE, Vol. 3, pp. 1401-1406, 2001.

[16] T.J.E, Miller, "Converter Volt-Ampere Requirements of the Switched Reluctance Motor Drive," IEEE Transactions, 1985, IA-21 1136-1144.

[17] H. Fazanehfard and R. Krishnan, "A fully controlled converter for switched reluctance motor," Proc. VPEC Ann. Sem., Nov.4, 1986, Virginia Tech., Blackburg, VA

[18] H. L. Huy, P. Viarouge, and K. Slimani, "A current controlled quasi-resonant converter for switched reluctance motor," IEEE, 1022-1028, 1990.

[19] M. Ehsani., I. Husain, K. R. Ramani, and J.H. Galloway, "Dual decay converter for switched reluctance motor drives in low voltage application," IEEE PESC, 620-624, 1991.

[20] R.W. De Donker, and J.P. Lyons, “An auxiliary quasiresonant dc link inverter for switched reluctance machines," EPE, 18-23, 1991.

[21] S. S. Park, and T.A. Lipo, "New series resonant conver for variable reluctance motor drives," IEEE PESC, 833-838, 1992.

[22] A. Hava, J.B. Wacknov, and T.A. Lipo, "New ZCS resonant Power converter topologies for variable reluctance machine drives," IEEE PESC, 432-439, 1993.

[23] D. H. Jang, I. Husain, and M. Ehsani, "Efficiency and performance analysis of the dual decay converter for switched reluctance motor drives," IEEE IAS, 658664, 1994.

[24] V. S. Gharpure, R. Krishnan R. Krishnan, and S. Lee, "Analysis and design of energy recovery snubbers for switched reluctance motor drives," IEES IAS, 10551062, 1994.

[25] E. S. Kim, K.C. Lee, G. H. Rim, and W. H. Kim, “A choppingless converter for switched reluctance motor with unity power factor and sinusoidal input current," IEEE PESC, 500-507, 1994.

[26] S. Vukosavi' and R. V. Stefanovic, "SRM Inverter Topologies : A Comparative Evaluation," IEEE Trans.
On Industry Appl, 27(6), pp1034-1047, 1991.

[27] S. Bolognami, E. Ognibeni, and M. Ziglitto, "Sliding Mode Control of the Energy Recovery Chopper in a C-Dump Switched Reluctance Motor Drive," IEEE Trans. On Industry Appl, 29(1), pp181-186, 1993.

[28] Z. Grbo, S. Vukosavic and E. Levi, "A novel power inverter for switched reluctance motor drives." Facta Universitatis (Nis), Ser: Elec Energ 18 (3) pp. 453465, 2005.

[29] X.D. Xue, K.W.E. Cheng and S.L. Ho, "Correlation of modeling techniques and power factor for switched reluctance machines drives," IEE Proc. Electr. Power Appl 152, pp. 710-722, 2005.

[30] X.D. Xue, K.W.E. Cheng and S.L. Ho, "Influences of output and control parameters on power factor of switched reluctance motor drive systems," Electr. Power Comp. Syst. 32, pp. 1207-1223, 2004.

[31] L. Chang, "Switched reluctance motors: small motors of the next generation for automobiles," Proceedings of IEEE Vehicular Technology Conference, Vol. 5, pp. 3316-3320, 2003.

[32] B.Y. Ma, T.H. Liu, C.G. Chen and Y.H. Chang, "Design and implementation of a switched reluctance motor drive with a novel converter," Electr. Power Syst. Res. 56, pp. 111-119, 2000.

[33] P. Vijayraghavan and R. Krishnan, "Front-end buck converter topology for SRM drives-design and control," Proceedings of the IEEE Industrial Applications Society (IECON), pp. 3013-3018, 2003.

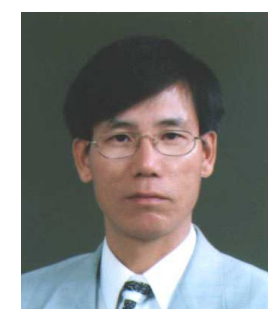

Jin-Woo Ahn was born in Busan, Korea in 1958. He received his B.S., M.S., and Ph.D. in Electrical Engineering from Pusan National University, Pusan, Korea in 1984, 1986, and 1992, respectively.

He has been with Kyungsung University, Busan, Korea as a professor in the

Department of Electrical and Mechatronics Engineering since 1992. He was a visiting researcher in the Speed Lab at Glasgow University, U.K., a visiting professor in the Dept. of ECE and WEMPEC at the University of Wisconsin-Madison, USA, and a visiting professor in the Dept. of ECE at Virginia Tech from July 2006 to June 2007. He was the director of the Advance Electric Machinery and Power Electronics Center. He has also been the director of the Smart Mechatronics Advanced Research and Training Center since August 2008 and the Senior Easy Life Regional Innovation System since July 2008, which are authorized by the Ministry of Knowledge Economy, Korea. $\mathrm{He}$ is the author of five books including SRM, the author of more than 100 papers and has several patents. His current research interests are advanced motor drive systems and electric vehicle drives.

Dr. Ahn has received several awards including the Best Paper Award from the Korean Institute of Electrical Engineers in 2002, The Korean Federation of Science and Technology Society in 2003 and Korean Institute of Power 
Electronics in 2007, respectively. He is a senior member of the Korean Institute of Electrical Engineers, a member of the Korean Institute of Power Electronics and a senior member of the IEEE.

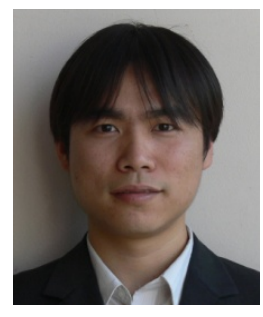

Jianing Liang was born in Zhuhai, China, in 1980. He received his B.S. degree in Electrical Engineering and Automation from Shenyang University of Technology, Shenyang, China, in 2003. He received his M.S. and $\mathrm{PhD}$ degree in Electrical and Mechatronics Engineering from Kyungsung University, Busan, Korea in 2007 and 2010, respectively. He is currently with Shenzhen Institutes of Advanced Technology, Chinese Academy of Science, Shenzhen, China, and The Chinese University of Hong Kong, as a research associate. His current research interests include advanced motor drive system and power converter.

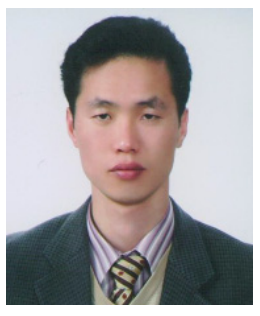

Dong-Hee Lee was born on Nov. 11, 1970 and received his B.S, M.S., and $\mathrm{PhD}$ in Electrical Engineering from Pusan National University, Busan, Korea in 1996, 1998, and 2001, respectively. He worked as a Senior Researcher for the Servo R\&D Team at OTIS-LG, from 2002 to 2005. He has been with Kyungsung University, Busan, Korea as an assistant professor in the Department of Mechatronics Engineering since 2005 . He has been the director of the Advance Electric Machinery and Power Electronics Center since 2009. His current research interests are Servo Systems and Electrical Motor Drives with Power Electronics. 